\title{
Bacterial Cell Surface Hydrophobicity Properties in the Mediation of In Vitro Adhesion by the Rabbit Enteric Pathogen Escherichia coli Strain RDEC-1
}

\author{
Brendan Drumm, ${ }^{\star}$ A. Wilhelm Neumann, ${ }^{\star \star}$ Zdenka Policova, ${ }^{\star \ddagger}$ and Philip M. Sherman \\ Division of Gastroenterology, Department of Pediatrics, Research Institute, ${ }^{*}$ The Hospital for Sick Children, and the \\ ${ }^{\ddagger}$ Department of Mechanical Engineering, University of Toronto, Toronto, Ontario, Canada M5G 1 X8
}

\begin{abstract}
The role of hydrophobicity in the attachment of enteropathogens to gastrointestinal mucosa is controversial. In vitro binding of Escherichia coli RDEC-1 to rabbit intestine is dependent on the expression of pili. We examined in vitro adherence of piliated RDEC-1 after altering either the hydrophobicity of the organisms, the hydrophobicity of the substrate for attachment, or the surface tension of the suspending liquid. Hydrophobicity of RDEC-1 was determined using four complementary methods. In each assay piliated RDEC-1 demonstrated relatively more hydrophobic properties compared with both organisms grown to suppress pilus expression and a mutant that cannot express mannose-resistant pili. When piliated RDEC-1 were pretreated with tetramethyl urea to disrupt hydrophobic bonds surface hydrophobicity decreased. Concurrently, bacterial adherence to rabbit ileal microvillus membranes, mucus and mucin was reduced. Binding of piliated organisms to hydrophobic surfaces was significantly higher compared to both nonpiliated bacteria and the adherence of piliated RDEC-1 to relatively hydrophilic surfaces. Addition of propanol reduced the surface tension of the suspending liquid, and decreased adhesion of piliated RDEC-1 to polystyrene by $80 \%$. Conversely, adherence of piliated organisms to a hydrophilic surface increased 12-fold after lowering the surface tension of the suspending liquid. We conclude that hydrophobic properties have a role in mediating in vitro adherence of this $E$. coli enteric pathogen.
\end{abstract}

\section{Introduction}

Adherence of bacteria to mucosal surfaces is an important virulence factor in infections of the gastrointestinal (1), respiratory (2), and genitourinary tracts (3). The ability of organisms to attach to these surfaces is often critical for the initiation of bacterial surface colonization (4-6). Adherence is, in general, mediated by two distinct mechanisms. Firstly, specific bacterial colonization factors, or adhesins, can act as ligands to mediate attachment of the organisms to specific receptors that are present on mucosal surfaces (6). For example, $P$ pili ex-

Presented in part at the Symposium on Surface and Transport Phenomena in Bioparticle Adhesion at the Third Chemical Congress of the North American Continent, Toronto, Canada, June 1988.

Address reprint requests to Dr. Sherman, Division of Gastroenterology (Room 1448), The Hospital for Sick Children, 555 University Avenue, Toronto, Ontario M5G 1X8, Canada.

Received for publication 30 October 1988 and in revised form 27 June 1989.

J. Clin. Invest.

(c) The American Society for Clinical Investigation, Inc. $0021-9738 / 89 / 11 / 1588 / 07 \$ 2.00$

Volume 84, November 1989, 1588-1594 pressed by certain strains of uropathogenic Escherichia coli bind to a specific digalactose receptor that is contained in the glycolipid fraction of apical membranes in human uroepithelial cells (3). Secondly, bacteria can also bind to mucosal surfaces by a less specific mechanism that is mediated by the interaction of hydrophobic domains (7). For example, adherence of oral bacteria to dental surfaces correlates with increasing cell surface hydrophobicity of the organisms $(8,9)$. These two mechanisms of adherence are not mutually exclusive since both hydrophobic forces and ligand-receptor interactions may participate in the adherence of bacteria to substrates (10).

Little information is currently available on the role of cell hydrophobicity in mediating the attachment of enteric pathogens to mucosal surfaces. A well-characterized rabbit pathogen, $E$. coli strain RDEC-1 (serotype $\mathrm{O} 15: \mathrm{H}-$ ) is a noninvasive, nonenterotoxigenic bacterium that attaches to intestinal epithelial cells in the ileum, cecum, and colon (11). Attachment of RDEC-1 is morphologically identical to the attachment of enteropathogenic $E$. coli to enterocytes in human infants (12-15). The organisms adhere to the surface of epithelial cells in a manner referred to as attaching and effacing adherence (13) in which there is focal destruction of microvilli on the apical surface of enterocytes (12-15). In vitro binding of RDEC-1 to ileal microvillus membranes and luminal glycoproteins is dependent on bacterial expression of hair-like, protein appendages that are variously referred to as pili, fimbriae, and bacterial lectins $(16,17)$. In this study, we examined the role of cell hydrophobicity in the adherence of RDEC-1 to specific solid surfaces and to mucosal preparations derived from rabbit ileum.

\section{Methods}

\section{Bacteria and growth conditions}

Stock cultures of E. coli strain RDEC-1 (serotype O15:H-) were held on trypticase soy agar slants at $4^{\circ} \mathrm{C}$. Organisms were grown in static, nonaerated Penassay broth (Difco Laboratories, Detroit, MI) to promote expression of mannose-resistant pili, previously designated AF/R1 (18). Expression of pili was confirmed by both slide agglutination of bacteria using AF/R1 pilus-specific antiserum (19) and transmission electron microscopy after negative staining of organisms with $2 \%$ phosphotungstic acid (20). To suppress phenotypic expression of AF/R1 pili; organisms were grown in Brain Heart Infusion broth (Difco) as described $(16,17)$. Strain M34 (kindly provided by Dr. M. Wolf and Dr. E. Boedeker, Walter Reed Army Institute of Research, Washington, DC) is an isogenic mutant of RDEC-1 in which Tn5 insertions into the plasmid encoding for $A F / R I$ pili results in the loss of pilus expression (21). As shown in Fig. 1, outer membrane profiles of piliated RDEC-1 and M34 were similar after growth of the organisms in Penassay broth in either the presence $(0.5 \mathrm{mg} / \mathrm{ml})$ or absence of an iron chelator, ovotransferrin (22). As described previously (23), outer membranes were precipitated from bacterial extracts using $N$-lauroyl sarcosine $(1.7 \% \mathrm{wt} / \mathrm{vol})$, separated by SDS-PAGE and then stained with silver reagent (Bio-Rad Laboratories, Richmond, CA). 
1

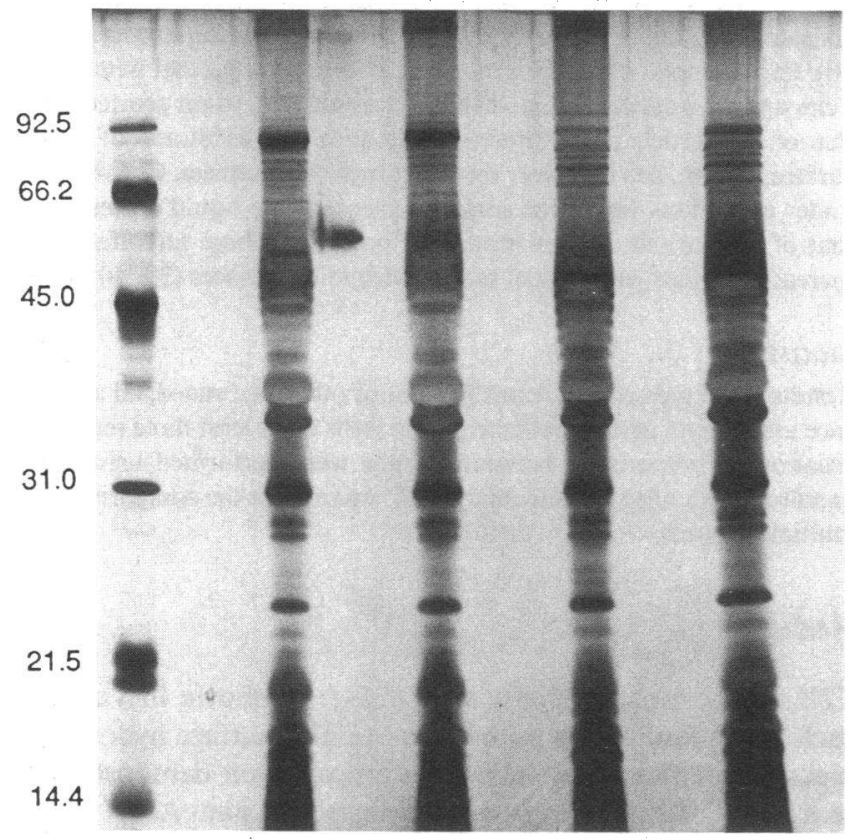

Figure 1. Silver stain of $12.5 \%$ polyacrylamide gel after electrophoresis in the presence of $0.1 \%$ SDS demonstrates that the outer membrane profiles of RDEC-1 (lane 2) and M34 (lane 3) grown in Penassay broth were similar. Growth in iron restricted broth, using the chelator ovotransferrin $(0.5 \mathrm{mg} / \mathrm{ml})$ resulted in expression of protein bands by both RDEC-1 (lane 4) and M34 (lane 5). Lane 1 contained known molecular weight standards (kilodaltons).

Bacteria were radiolabeled by supplementing $10 \mathrm{ml}$ broth cultures with $100 \mu \mathrm{Ci}$ of sterile $\left[{ }^{3} \mathrm{H}\right]$ thymidine (specific activity $15.7 \mathrm{Ci} / \mathrm{mmol}$, New England Nuclear, Boston, MA). Broth cultures were incubated overnight at $37^{\circ} \mathrm{C}$ and harvested by centrifugation at $2,500 \mathrm{~g}$ for 15 min. After two washes in sterile PBS, pH 7.4 at $25^{\circ} \mathrm{C}$, to remove nonincorporated radioisotope, bacteria were resuspended in PBS at a concentration of $5 \times 10^{9} / \mathrm{ml}$.

\section{Measurements of bacterial cell hydrophobicity}

Hydrophobic interaction chromatography (HIC). ${ }^{1}$ Retention of bacteria on phenyl-Sepharose columns (Pharmacia, Uppsala, Sweden) was performed as described by Smyth et al. (24). Increased retention of bacteria on the phenyl-Sepharose columns correlates with increased cell surface hydrophobicity. RDEC-1 and M34 were resuspended in PBS to a concentration of $1 \times 10^{9} / \mathrm{ml}$. A $0.1-\mathrm{ml}$ aliquot of this suspension was added to $4.9 \mathrm{ml}$ of PBS and the optical density of this initial suspension was measured spectrophotometrically at $600 \mathrm{~nm}$. A second $0.1-\mathrm{ml}$ aliquot was applied to a phenyl-Sepharose column $(0.6 \times 3.0$ $\mathrm{cm}$; Pharmacia, Toronto, Ontario) and the column then washed with $4.9 \mathrm{ml}$ of PBS. The optical density (OD) of the eluent was also determined at $600 \mathrm{~nm}$. The percentage of RDEC- 1 and M34 retained on the column was calculated using the formula described by Boedeker and Cheney (25): 100 - OD (Eluent)/OD (Initial) $\times 100$.

Salt aggregation test (SAT). The SAT was performed by slide agglutination of bacteria with varying concentrations of ammonium sulfate, as described (19). In this assay, surface hydrophobicity is inversely correlated with the salt concentration that is required to mediate agglutination of bacteria. Bacteria agglutinated by concentrations of ammonium sulfate of $1 \mathrm{M}$ or less are defined as hydrophobic (26). RDEC-1

1. Abbreviations used in this paper: HIC, hydrophobic interaction chromatography; SAT, salt aggregation test; TMU, tetramethyl urea. and M34 were suspended in PBS at a concentration of $5 \times 10^{8} / \mathrm{ml}$. A $0.025-\mathrm{ml}$ aliquot of each bacterial suspension was mixed on glass microscope slides with an equal volume of ammonium sulfate at concentrations varying between $0.0625 \mathrm{M}$ and $4 \mathrm{M}$. The slides were gently rotated by hand and observed visually after $2 \mathrm{~min}$ for the presence of bacterial aggregation.

Adherence to polystyrene. Adherence of RDEC-1 and M34 to polystyrene was determined by adding $10^{9}$ radiolabeled bacteria in 0.4 $\mathrm{ml}$ to wells that were formed by the fusing of a polystyrene film to the underside of teflon blocks in which cylindrical holes were cut (see adherence assay below). Bacteria were incubated in the polystyrene wells for $1 \mathrm{~h}$ at $37^{\circ} \mathrm{C}$. After removal of unbound bacteria by two washings with PBS, adherent bacteria were removed using the detergent $1 \%$ SDS. Adherent bacteria released by the detergent were then quantitated by counting disintegrations per minute in a beta scintillation counter. There is a positive correlation between adherence of bacteria to polystyrene and the cell surface hydrophobicity of the organism (27).

Contact angle measurements. The technique for contact angle measurements, referred to as axisymmetric drop shape analysis, contact diameter (ADSA-CD), was performed, as described in detail elsewhere $(28,29)$. The method calculates contact angle by solving the Laplace equation, using liquid surface tension, drop volume, and the contact diameter of the water drop as input parameters. The main experimentally determined parameter is the radius of the drop. A layer of bacteria was prepared by the filtration of $5.0 \mathrm{ml}$ of $5 \times 10^{10}$ bacteria suspended in phosphate buffer through a membrane filter with a pore size of 0.45 $\mu \mathrm{m}$ (Black MSI, Microsep; Fisher Scientific, Ottawa, Ontario, Canada). The filter containing the layer of bacteria was then placed onto $2 \%$ solidified agar which acted as a water reservoir to prevent drying. Sessile drops of distilled water were placed onto the layer of bacteria. The volume of the sessile drops was obtained by using a micrometer syringe (Gilmont, Canlab, Toronto, Canada) that delivers drops with an accuracy of $0.022 \mu \mathrm{l}$. The surface tension of the distilled water was determined by the Wilhelmy technique (30). The contact diameter of the drop was determined by computerized digitalization of the drop periphery on an image taken from above. The drop image was obtained using a stereomicroscope (M7S Zoom, Wild Heerbrugg, Federal Republic of Germany). The first contact diameter measurement was obtained $5 \mathrm{~min}$ after the layer of bacteria was formed; further measurements were performed at 5 -min intervals for up to $100 \mathrm{~min}$. The surface tension of the bacteria was calculated using the equation of state as described by Neumann et al. (31).

\section{Intestinal membrane preparations}

Preparation of both crude mucus and purified mucin from rabbit ileum was performed, as described previously (32). Briefly, ilea of $1 \mathrm{~kg}$, specific pathogen-free male New Zealand white rabbits were removed from the abdomen, extensively rinsed with cold saline, and the intestines were opened longitudinally. Mucosal scrapings were collected by lightly scraping the mucosa using glass microscope slides and placed into a solution that contained proteinase inhibitors to minimize proteolytic digestion of native mucins. After homogenization in a Waring blendor for $30 \mathrm{~s}$, the homogenate was centrifuged at $30,000 \mathrm{~g}$ for 30 min to remove cellular debris. The supernatant was defined as the crude mucus preparation. Mucus glycoprotein of goblet cell origin was purified from the crude mucus preparation by ultracentrifugation in cesium chloride, as described $(32,33)$.

Right-side-out apical microvillus membranes of enterocytes were prepared from rabbit ileum using the calcium chloride precipitation method first described by Kessler et al. (34). Mucus, mucin, and microvillus membranes were suspended in sterile PBS at a final concentration of $1 \mathrm{mg} / \mathrm{ml}$ using the protein determination method of Lowry et al. (35).

\section{Bacterial adherence assay}

Adherence of RDEC-1 and M34 to substrates was determined using our modification (32) of a method first described by Laux et al. (36). 
Briefly, $0.4 \mathrm{ml}$ of the crude mucus, purified mucin, and microvillus membrane preparations were incubated in the wells of 96-well polystyrene tissue culture plates (Flow Laboratories, McLean, VA) overnight at $4^{\circ} \mathrm{C}$. After three washings with PBS to remove unbound substrate, residual binding sites in the wells were blocked by the addition of $0.4 \mathrm{ml}$ of 1\% BSA (Sigma Chemicals, St. Louis, MO) and incubation overnight at $4^{\circ} \mathrm{C}$. After three washings with PBS, $10^{9}$ radiolabeled bacteria, suspended in $0.4 \mathrm{ml}$ of PBS, were added to the wells. After incubation for $1 \mathrm{~h}$ at $37^{\circ} \mathrm{C}$ nonadherent bacteria were removed by three washings of PBS. To remove the adherent bacteria $0.4 \mathrm{ml}$ of the detergent SDS (1\%) was added to the wells and incubated for $3 \mathrm{~h}$ at $37^{\circ} \mathrm{C}$. Samples were then removed, placed in $10 \mathrm{ml}$ of scintillation fluid (Aquasol II; New England Nuclear, Boston, MA) and extracted radioactivity was determined by counting disintegrations per minute in a beta scintillation counter (model LS7500; Beckman Instruments, Inc., Palo Alto, CA). In preliminary experiments, we compared the radioactivity contained in intact wells with the radioactivity obtained using the detergent extraction. SDS consistently removed $80 \%$ of the radioactivity bound to the polystyrene wells.

To examine the adhesion of RDEC-1 and M34 to glass, polystyrene, and sulfonated polystyrene the adherence assay was modified slightly. Glass microscope slides (Erie Scientific, Portsmouth, NH) were used directly from the box in which they were supplied. Cleaning of glass slides to produce a more hydrophilic surface was performed by incubation of the slides with chromic sulfuric acid solution (Fisher Scientific) overnight at room temperature. Slides were rinsed five times in distilled water, once in $\sim 100 \%$ ethanol and then dried in a dust-free environment. Polystyrene and sulfonated polystyrene surfaces were obtained as thin film sheets (Central Research Laboratory, Dow Chemical Co., Sarnia, Ontario, Canada). Before their use in the bacterial adherence assay, strips of polystyrene were washed for $10 \mathrm{~min}$ in $100 \%$ ethanol and dried in a dust-free environment. Sulfonated polystyrene was cleansed by dipping each strip in hexanes (Fisher Scientific Co., Fair Lawn, NJ) for $10 \mathrm{~s}$, as described (37). Microtiter wells were formed by fixing the polymer or glass surfaces to the underside of teflon blocks in which cylindrical holes were cut. The bacterial adherence assay was then performed as described above.

\section{Alteration of the surface hydrophobicity of piliated bacteria with tetramethyl urea}

Piliated RDEC-1 were suspended in PBS to which various concentrations (0.01-1.0 M final concentration) of tetramethyl urea (TMU; Sigma) were added, and then incubated for $1 \mathrm{~h}$ at $37^{\circ} \mathrm{C}(8)$. Adherence of bacteria to polystyrene, hydrophobic interaction chromatography and the salt aggregation test were used to examine the effects of TMU on the cell surface hydrophobicity properties of piliated RDEC-1. Viability of RDEC-1 in TMU was ensured by calculating the number of bacterial colony-forming units in the presence and absence of TMU.

\section{Alteration of the surface tension of the suspending liquid} Propanol (3.5\%) (Fisher Scientific, Fair Lawn, NJ) was added to PBS to lower surface tension (38). The surface tension of PBS alone and PBS with added propanol was measured using the Wilhelmy plate method, as described by Neumann and Good (30). The rationale for examining the adherence of RDEC-1 to various substrates when placed into liquids of different surface tensions was based on the thermodynamic consideration that free energy will be minimized at equilibrium (39, 40). For example, it has been previously demonstrated that when particles are suspended in a liquid that has a surface tension greater than that of the particle it will preferentially adhere to substrates of lower surface tension, i.e., relatively more hydrophobic surfaces. Conversely, under conditions where the surface tension of the liquid is less than that of the particle in suspension the particles adhere to surfaces of increased surface tension, i.e. more hydrophilic surfaces $(39,40)$.

\section{Statistics}

Results are expressed as mean \pm SE. Unless otherwise stated, all adherence assays were performed in triplicate wells on at least three separate occasions. Comparisons between groups were performed using the unpaired Student's $t$ test and analysis of variance for the comparison of multiple groups.

\section{Results}

Cell surface hydrophobicity of RDEC-1. As shown in Table I, each of the four assays we used to examine surface hydrophobicity properties of the rabbit enteropathogen demonstrated that RDEC-1, which expressed mannose-resistant AF/R1 pili, were more hydrophobic compared with both the same organisms grown under conditions to suppress pilus expression and the pilus-deficient mutant, strain M34. Significantly more RDEC-1, which expressed mannose-resistant pili were retained on a substituted phenyl-Sepharose column $(33.6 \% \pm 4.5)$ compared with nonpiliated organisms $(3.4 \% \pm 1.6, P<0.001)$ and M34 $(1.5 \% \pm 0.5, P<0.001)$. When expressing AF/RI pili, RDEC-1 were precipitated at a lower salt concentration ( 0.5 M) compared to both nonpiliated bacteria (4.0 M) and M34 (4.0 M). Expression of $A F / R 1$ pili also resulted in significantly greater adherence of bacteria to polystyrene $(10,387 \pm 1,822$ $\mathrm{dpm})$ than nonpiliated organisms $(849 \pm 217, P<0.01)$ and M34 (1,286 $\pm 331, P<0.01)$. Contact angle measurements were calculated serially over time between a drop of water and a layer of $A F / R 1$ piliated RDEC-1, nonpiliated bacteria or strain M34. The mean contact angle of water with piliated organisms, calculated from the measurements obtained at steady state, was $20.8^{\circ} \pm 0.9^{\circ}$ (mean $\pm 95 \% \mathrm{CL}$ ). In contrast, the mean contact angle of water with nonpiliated RDEC-1 was $10.6^{\circ} \pm 0.5^{\circ}(P<0.001)$ and with $\mathrm{M} 34,15.4^{\circ} \pm 0.3^{\circ}(P$ $<0.001$ ).

Effects of TMU on cell surface hydrophobicity and adherence properties of $R D E C-1$. After incubation of $A F / R 1$ piliated RDEC-1 with $0.4 \mathrm{M}$ TMU there was a marked reduction in cell surface hydrophobicity properties of the bacteria. As shown in Fig. 2 , this reduction was characterized by a decrease

Table I. Surface Hydrophobicity of Mannose-resistant, AF/R1 Piliated RDEC-1, RDEC-1 Grown to Suppress Phenotypic Expression of $A F / R 1$ pili, and M34 (Genetic Suppression of Pilus Expression)

\begin{tabular}{lccrc}
\hline \multicolumn{1}{c}{ E. coli strain } & $\begin{array}{c}\text { A HIC } \\
\text { (\% Retn.) }\end{array}$ & $\begin{array}{c}\text { B SAT } \\
\text { (M conc.) }\end{array}$ & $\begin{array}{c}\text { C Polystyrene } \\
\text { binding (DPM's) }\end{array}$ & $\begin{array}{c}\text { D Contact } \\
\text { angle of water ( }\end{array}$ \\
\hline Piliated RDEC-1 & $33.6 \pm 4.5$ & 0.5 & $10,387 \pm 1822$ & $20.8 \pm 0.9$ \\
Nonpiliated RDEC-1 & $3.5 \pm 1.6 \%^{*}$ & 4.0 & $849 \pm 217^{\ddagger}$ & $10.6 \pm 0.5^{*}$ \\
M34 & $1.5 \pm 0.4 \%^{*}$ & 4.0 & $1,286 \pm 331^{\ddagger}$ & $15.4 \pm 0.3^{*}$ \\
\hline
\end{tabular}

Cell hydrophobicity was determined by hydrophobic interaction chromatography $(A)$, the salt aggregation test $(B)$, binding of organisms to polystyrene microtiter wells $(C)$, and contact angle with a droplet of water $(D)$. Results are expressed as mean $\pm \mathrm{SE}$. ${ }^{*} P<0.001{ }^{\ddagger} P<0.01$. 

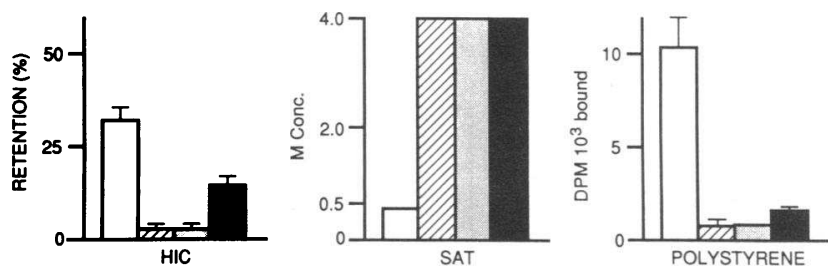

Figure 2. Cell hydrophobicity of RDEC-1 and M34 determined by hydrophobic interaction chromatography (HIC), the salt aggregation test (SAT), and bacterial adherence to polystyrene (Polystyrene). Incubation in TMU (closed bars) resulted in a reduction in hydrophobicity of piliated bacteria. The differences between HIC results and adherence to polystyrene seen with nonpiliated (hatched bars), M34 (screened bars), and TMU-treated (closed bars), bacteria in comparison to piliated organisms (open bars) are significant $(P<0.01)$.

in the number of TMU-treated piliated organisms retained on phenyl-Sepharose columns $(P<0.01)$, a decrease in the number of piliated bacteria adherent to polystyrene $(P<0.01)$, and an increase in the molar concentration of ammonium sulphate required to precipitate the piliated organisms. The reduction in cell surface hydrophobicity of piliated RDEC-1 by TMU was dose dependent. While adherence of the organisms to polystyrene was reduced by $50 \%$ when preincubated with 0.01 M TMU, maximum inhibition ( $16 \%$ of control) was obtained at $0.4 \mathrm{M}$ TMU. After treatment of piliated RDEC-1 with TMU in concentrations up to $1.0 \mathrm{M}$, the organisms remained fully viable. In addition, the bacteria continued to express mannose-resistant pili, as evidenced by both slide agglutination of bacteria with anti-AF/RI pilus antiserum and transmission electron microscopy (Fig. 3). Washing of organisms with PBS did not reverse the effects of TMU on bacterial cell surface hydrophobicity. For example, after three washings in PBS binding of TMU-treated piliated RDEC-1 to polystyrene was only $17 \%$ of initial levels.

The effects of incubation with TMU on adherence of pi- liated RDEC-1 to microvillus membranes, crude mucus, and purified mucin derived from rabbit ileum was then quantitated. Similar to our previous findings, in vitro binding of RDEC-1 to microvillus membranes (19), crude mucus (17), and purified mucin (32) was dependent on bacterial expression of AF/R1 pili (Fig. 4). After incubation of piliated RDEC-1 with $0.4 \mathrm{M}$ TMU, binding of organisms to each of the three substrates was significantly reduced (Fig. 4).

Binding of piliated RDEC-1 to surfaces of varying hydrophobicity. Adherence of RDEC-1 expressing AF/R1 pili to sulfonated polystyrene was examined because it is a relatively hydrophilic surface compared with polystyrene, which is a known hydrophobic surface (40). As shown in Fig. 5, binding of piliated RDEC-1 to polystyrene was fivefold greater compared with binding of the organisms to sulfonated polystyrene $(P<0.001)$. Adherence of piliated RDEC-1 to slides before and after cleansing of the glass surfaces with chromic acid was also examined since chromic acid washing renders glass surfaces more hydrophilic. Adherence of the piliated organisms to cleaned glass was only $30 \%$ of the levels of bacterial binding to untreated glass slides (Fig. 5, $P<0.01$ ).

Effects of altering surface tension of the suspending liquid on adherence of RDEC-1. Measured by the Wilhelmy plate method the surface tension of PBS was $72 \mathrm{~mJ} / \mathrm{m}^{2}$. The surface tension of PBS was lowered to $55 \mathrm{~mJ} / \mathrm{m}^{2}$ after the addition of $3.5 \%$ propanol. Using the equation of state (31), the surface tension of piliated RDEC-1 calculated from the contact angle measurements was $68.1 \pm 0.3$. Therefore, after the addition of $3.5 \%$ propanol the organisms were suspended in a liquid with a surface tension that was less than the surface tension of the bacteria. In direct contrast to the findings with piliated RDEC-1 suspended in PBS, AF/R1 piliated organisms that were suspended in PBS plus propanol adhered maximally to sulfonated polystyrene and binding of bacteria was only minimal to the more hydrophobic polystyrene surface (Fig. 6). The viability of organisms was not affected by the presence of $3.5 \%$ propanol.

\section{a}

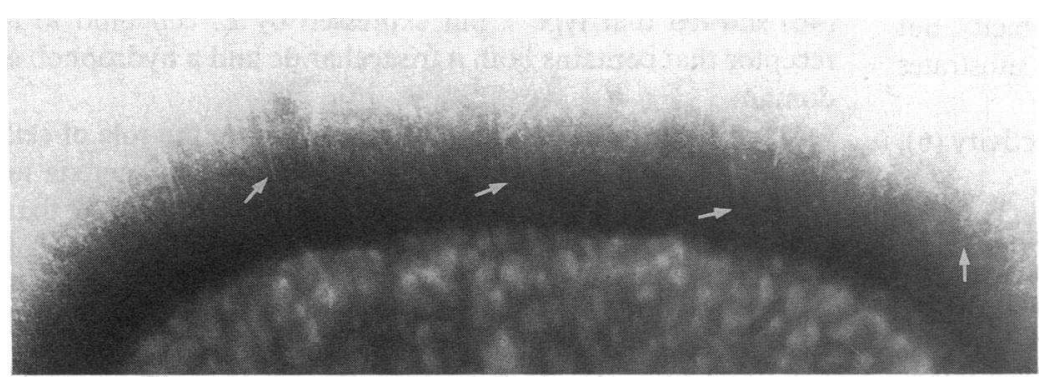

b

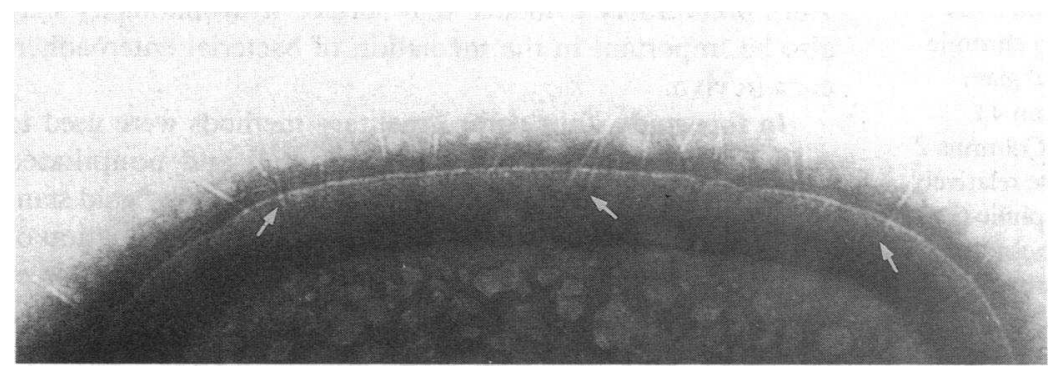

Figure 3. Transmission electron photomicrographs showing pili (arrows) on the surface of RDEC-1 grown in Penassay broth either alone $(A)$ or in the presence of $0.4 \mathrm{M}$ TMU $(B)$. Bacteria were placed onto Formvar-coated copper grids, stained with $2 \%$ phosphotungstic acid and examined in a Philips 300 transmission electron microscope at an accelerating voltage of $80 \mathrm{kV}$. 


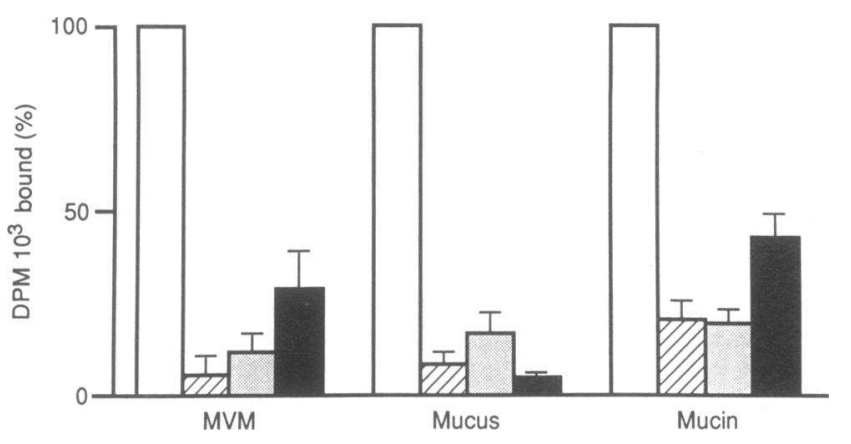

Figure 4. Binding of piliated RDEC-1 (open bars), nonpiliated RDEC (hatched bars), M34 (screened bars), and TMU-treated piliated organisms (closed bars) to microvillus membranes (MVM), crude mucus, and purified mucin of rabbit ileum. After preincubation with TMU (0.4 M) adherence of piliated RDEC-1 was diminished $(P<0.05)$. Results are expressed as the percentage of binding of piliated organisms in the absence of TMU.

\section{Discussion}

In this study we have shown that surface hydrophobicity of RDEC-1 is an important factor in the in vitro attachment of this enteric pathogen to surfaces such as microvillus membranes, crude mucus, and purified goblet cell mucin derived from rabbit ileum. The findings also confirmed that surface hydrophobicity of RDEC-1 is enhanced by the bacterial expression of mannose-resistant, AF/R 1 pili. We have previously shown that in vitro binding of RDEC-1 to microvillus membranes (19), crude mucus (17), and purified mucin (32) is pilus dependent. In this study we also used M34, a mutant derived from RDEC-1, which is incapable of pilus expression, to provide further support of the role of $A F / R 1$ pili in bacterial adherence in vitro.

Previous studies have examined the potential role of cell surface hydrophobicity in attachment of microorganisms to mucosal surfaces $(8,9)$. However, these studies were based only on the evaluation of bacterial adherence to substrates after hydrophobicity was altered. We evaluated the role of hydrophobicity in mediating the adherence of an enteric pathogen not only by altering bacterial surface hydrophobicity, but also by varying both the surface properties of the substrates and the surface tension of the suspending liquid.

Since bacterial adherence is associated with infectivity (6),

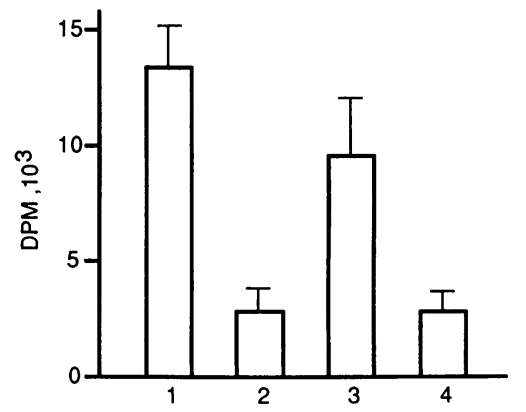

Figure 5. Adherence of $\mathrm{AF} / \mathrm{R} 1$ piliated

RDEC-1 to polystyrene (column 1) in comparison to sulphonated polystyrene (column 2) $(P<0.001)$, and glass slides (column 3) as compared to chromic acid cleansed glass slides (column 4) $(P<0.01)$. Columns 2 and 4 are the relatively more hydrophilic (i.e., less hydrophobic) substrates. Results are expressed as dpm, mean \pm SE.

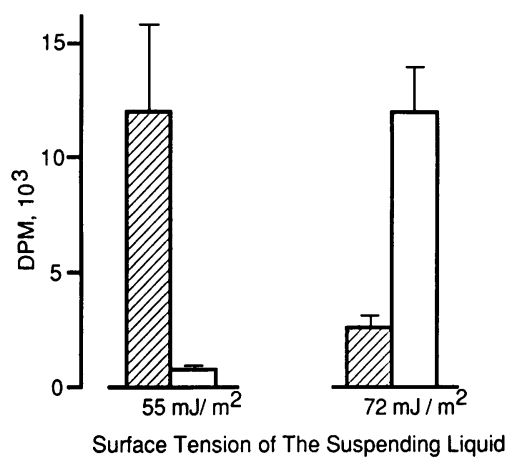

Figure 6. Adherence of piliated RDEC-1 when the organisms were suspended in either PBS with $3.5 \%$ propanol (surface tension 55 $\mathrm{mJ} / \mathrm{m}^{2}$ ) or suspended in PBS alone (surface tension $72 \mathrm{~mJ} / \mathrm{m}^{2}$ ). Bacterial binding to polystyrene ( $\square$ ) is indicated by the open bar histograms and adherence of bacteria to the relatively

more hydrophilic sulphonated polystyrene (园) by the hatched bars. Results are expressed as dpm, mean $\pm \mathrm{SE}$. The increase in adherence to sulphonated polystyrene $(P<0.01)$ and the decrease in adherence to polystyrene $(P<0.001)$ after suspension of bacteria in a $3.5 \%$ propanol solution are both significant.

recent interest has focused on the identification of specific receptors to which bacterial adhesins adhere. For example, Ofek et al. $(41,42)$ demonstrated that lectin-mediated binding of $E$. coli, which express mannose-sensitive, type 1 pili, is mediated by an alpha-linked mannosyl receptor contained in glycoprotein constituents of surface membranes. Subsequently, Dean and Isaacson (43) isolated a low molecular weight glycoprotein receptor from rabbit intestinal brush borders to which mannose-resistant pili expressed by certain other $E$. coli strains adhere. In the urinary tract, O'Hanley et al. (3) showed that uropathogenic $E$. coli express mannose-resistant pili that bind to digalactose receptors contained in the glycolipid fraction of the plasma membrane of uroepithelial cells.

Other studies suggest that hydrophobic interactions may also play a role in mediating the adherence of bacteria to mucosal surfaces $(44,45)$. For example, several studies show that surface hydrophobicity of microorganisms in the oral cavity is an important factor in the adherence of bacteria to dental surfaces $(8,9)$. Of course, it is possible that specific ligand-receptor binding and nonspecific hydrophobic interactions are both important factors in bacterial adherence (10). Firon et al. (46) showed that type 1 pili expressed by $E$. coli bind to a receptor that contains both a trisaccharide and a hydrophobic domain.

However, little attention has been given to the role of cell surface hydrophobicity in mediating adherence of bacteria to the intestinal epithelium. Wadstrom et al. (47) showed that increased hydrophobicity of enterotoxigenic $E$. coli strains of both human and animal origin was dependent on pilus expression. Of interest, the same group subsequently reported that a hydrophobic liquid fed to rabbits after their inoculation with an enterotoxigenic $E$. coli had a protective effect against the development of diarrhea (48). Their study, therefore, provides preliminary evidence that surface hydrophobicity may also be important in the mediation of bacterial enteroadherence in vivo.

In this study, four complementary methods were used to assess surface hydrophobicity of piliated and nonpiliated RDEC-1 since no one method is established as the "gold standard." Other authors suggest that the use of a combination of in vitro techniques is most appropriate. For example, Dillon et al. (49) compared different methods of measuring cell surface hydrophobicity and they concluded that reliance on one 
method for determining bacterial hydrophobicity is inadequate. After comparing five different methods Mozes and Rouxhet (50) concluded that contact angle measurements in combination with hydrophobic interaction chromatography and adhesion to polystyrene provided the most accurate indication of the cell surface hydrophobicity of bacteria.

In this study TMU reduced hydrophobicity, but not the viability, of piliated RDEC-1. Adherence of RDEC-1, which expressed mannose-resistant, $\mathrm{AF} / \mathrm{RI}$ pili to various substrates decreased after the incubation of bacteria with TMU. This finding also suggests that hydrophobicity plays a significant role in mediating the adherence of this enteric pathogen. However, in addition to its effects on cell hydrophobicity TMU could theoretically also alter other, as yet unidentified, surface properties of the organisms. Therefore, to support our initial observations, we also used two other methods to evaluate hydrophobic interactions that did not involve changing the cell surface properties of the bacteria. Rather, these experiments involved changes in either the surface properties of the substrate or the surface tension of the suspending liquid medium. Sulfonated polystyrene is a hydrophilic surface in comparison to polystyrene (40). Similarly, cleansing of glass with chromic acid renders the surface hydrophilic in comparison to standard glass surfaces. In this study, RDEC- 1 that expressed pili bound to the two hydrophobic surfaces but they showed only minimal adherence to more hydrophilic test surfaces.

Absolom et al. (39) reported that bacteria will bind maximally to substrates of low surface tension only when they are suspended in a liquid that has a surface tension greater than that of the bacteria. Conversely, bacteria bind to substrates of high surface tension when the organisms are suspended in a liquid with a surface tension less than that of the bacteria. In the present study, when propanol was added to PBS to lower the surface tension of the suspending liquid there was a complete reversal in the characteristics of binding of piliated RDEC-1 to polystyrene and sulfonated polystyrene (Fig. 6).

In summary, these observations provide evidence for the importance of cell surface hydrophobicity in mediating the attachment of an $E$. coli enteropathogen in vitro. Future studies will examine the importance of cell hydrophobicity for enteroadherence of the rabbit pathogen, $E$. coli strain RDEC-1, during infection in vivo.

\section{Acknowledgments}

This work was supported by a grant from the Canadian Foundation for Ileitis and Colitis and the Variety Club of Toronto. B. Drumm is the recipient of an Elizabeth Arbuthnot Dyson Fellowship and an American Gastroenterological Association research training supplement. P. Sherman is the recipient of a Career Scientist Award from the Ontario Ministry of Health, Research Personnel Development Program.

\section{References}

1. Boedeker, E. C. 1982. Enterocyte adherence of Escherichia coli. its relation to diarrheal disease. Gastroenterology. 83:489-492.

2. Ramphal, R., J. C. Sadoff, M. Pyle, and J. D. Silipigni. 1984. Role of pili in the adherence of Pseudomonas aeruginosa to injured tracheal epithelium. Infect. Immun. 44:38-40.

3. O'Hanley, P., D. Low, I. Romero, D. Lark, K. Vosti, S. Falkow, and G. Schoolnik. 1985. Gal-Gal binding and hemolysin phenotypes and genotypes associated with uropathogenic Escherichia coli. N. Engl. J. Med. 313:414-20.
4. Smith, H. 1977. Microbial surfaces in relation to pathogenicity. Bacteriol. Rev. 41:475-500.

5. Gibbons, R. J., and J. Van Haute. 1980. Bacterial adherence and the formation of dental plaques. In Bacterial Adherence. E. H. Beachey, editor. Chapman and Hall, London. 60-104.

6. Beachey, E. H. 1981. Bacterial adherence: adhesin-receptor interaction mediating the attachment of bacteria to mucosal surfaces. $J$. Infect. Dis. 143:325-345.

7. Magnusson, K. E. 1982. Hydrophobic interaction-a mechanism of bacterial binding. Scand. J. Infect. Dis. Suppl. 33:32-36.

8. Weerkamp, A. H., H. C. Van Der Mei, and J. W. Slot. 1987. Relationship of cell surface morphology and composition of Streptococcus salivarius $\mathrm{K}^{+}$to adherence and hydrophobicity. Infect. Immun. 55:438-45.

9. Weiss, E., M. Rosenberg, H. Judes, and E. Rosenberg. 1982. Cell surface hydrophobicity of adherent oral bacteria. Curr. Microbiol. $1: 125-128$.

10. Busscher, H. J., and A. H. Weerkamp. 1987. Specific and non-specific interactions in bacterial adhesion to solid substrata. FEMS (Fed. Eur. Microbiol. Soc.) Lett. 46:165-173.

11. Sherman, P., and E. Boedeker. 1987. Regional differences in attachment of enteroadherent Escherichia coli strain RDEC-1 to rabbit intestine: Luminal colonization but lack of mucosal adherence in jejunal self-filling blind loops. J. Pediatr. Gastroenterol. Nutr. 6:439444.

12. Takeuchi, A., L. R. Inman, P. D. O'Hanley, J. R. Cantey, and W. B. Lushbaugh. 1978. Scanning and transmission electron microscopic study of Escherichia coli O15 (RDEC-1) enteric infection in rabbits. Infect. Immun. 19:686-694.

13. Moon, H. W., S. C. Whipp, R. A. Argenzio, M. M. Levine, and R. A. Giannella. 1983. Attaching and effacing activities of rabbit and human enteropathogenic Escherichia coli in pig and rabbit intestines. Infect. Immun. 41:1340-1351.

14. Ulshen, M. H., and J. L. Rollo. 1980. Pathogenesis of Escherichia coli gastroenteritis in man-another mechanism. N. Engl. J. Med. 302:99-101.

15. Rothbaum, R., A. J. McAdams, R. Giannella, and J. C. Partin. 1982. A clinico-pathologic study of enterocyte-adherent Escherichia coli: a cause of protracted diarrhea in infants. Gastroenterology. 83:441-54.

16. Cheney, C. P., S. B. Formal, P. A. Schad, and E. C. Boedeker. 1983. Genetic transfer of a mucosal adherence factor (R1) from an enteropathogenic Escherichia coli strain into a Shigella flexneri strain and the phenotypic suppression of the adherence factor. J. Infect. Dis. 147:711-723.

17. Sherman, P. M., and E. C. Boedeker. 1987. Pilus-mediated interaction of the Escherichia coli strain RDEC-1 with mucosal glycoproteins in the small intestine of rabbits. Gastroenterology. 93:734743.

18. Berendson, R., C. P. Cheney, P. H. Schad, and E. C. Boedeker. 1983. Species-specific binding of purified pili (AF/R1) from the Escherichia coli RDEC-1 to rabbit intestinal mucosa. Gastroenterology. 85:837-845

19. Sherman, P. M., W. L. Houston, and E. C. Boedeker. 1985. Functional heterogeneity of intestinal Escherichia coli strains expressing type 1 somatic pili (fimbriae): assessment of bacterial adherence to intestinal membranes and surface hydrophobicity. Infect. Immun. 49:794-804.

20. Sherman, P., R. Soni, and H. Yeger. 1988. Characterization of flagella purified from enterohemorrhagic, Vero-cytotoxin-producing Escherichia coli serotype 0157:H7. J. Clin. Microbiol. 26:1367-1372.

21. Wolf M. K., G. P. Andrews, D. L. Fritz, R. W. Sjogren, Jr., and E. C. Boedeker. 1988. Characterization of the plasmid from Escherichia coli RDEC-1 that mediates expression of adhesin AF/R1 and evidence that $A F / R 1$ pili promote but are not essential for enteropathogenic disease. Infect. Immun. 56:1846-1857.

22. Stevenson, P., and E. Griffiths. 1985. Growth of Escherichia coli under iron-restricted conditions. In The Virulence of Escherichia 
coli, Reviews and Methods. M. Sussman, editor. Academic Press, London. 413-417.

23. Sherman, P. M., and R. Soni. 1988. Adherence of Vero-cytotoxin-producing Escherichia coli of serotype 0157:H7 to human epithelial cells in tissue culture: role of outer membranes as bacterial adhesins. J. Med. Microbiol. 26:11-17.

24. Smyth, C. J., P. Jonsson, E. Olsson, O. Söderlind, J. Rosengren, S. Hjerten, and T. Wadstrom. 1978. Differences in hydrophobic surface characteristics of porcine enteropathogenic Escherichia coli with or without $\mathrm{K} 88$ antigens as revealed by hydrophobic interaction chromatography. Infect. Immun. 22:462-472.

25. Boedeker, E. C., and C. P. Cheney. 1983. Hydrophobic bacterial surface properties are determined by pili which mediate attachment to intestinal brush border membranes. In Affinity Chromatography and Biological recognition. I. M. Chaiken, M. Wilchek, and I. Parikh, editors. Academic Press, New York. 501-502.

26. Lindahl, M., A. Faris, T. Wadstrom, and S. Hjerten. 1981. A new test based on 'salting out' to measure relative surface hydrophobicity of bacterial cells. Biochim. Biophys. Acta. 677:471-476.

27. Rosenberg, M. 1981. Bacterial adherence to polystyrene: a replica method of screening for bacterial hydrophobicity. Appl. Environ. Microbiol. 42:375-377.

28. Duncan-Hewitt, W. C., Z. Policova, P. Cheng, E. I. VarghaButler, and A. W. Neumann. 1989. Semiautomatic measurement of contact angles on cell layers by a modified axisymmetric drop shape analysis. Colloids and Surfaces. In press.

29. Skinner, F. K., Y. Rotenberg, and A. W. Neumann. 1989. Contact angle measurements from the contact diameter of sessile drops by means of a modified axisymmetric drop shape analysis. $J$. Colloid Interface Sci. 130:25-34.

30. Neumann, A. W., and R. J. Good. 1979. Techniques of measuring contact angles. In Surface and Colloid Science II Experimental Methods. R. J. Good and R. R. Stromberg, editors. Plenum Press, New York. 31-91.

31. Neumann, A. W., R. J. Good, C. J. Hope, and M. Sejpal. 1974. An equation of state approach to determine surface tensions of low energy solids from contact angles. J. Colloid Interface Sci. 49:291-304.

32. Drumm, B., A. Roberton, and P. Sherman. 1988. Inhibition of attachment of Escherichia coli RDEC-1 to intestinal microvillus membranes by rabbit ileal mucus and mucin in vitro. Infect. Immun. 56:2437-2442.

33. Mantle, M., and A. Allen. 1981. Isolation and characterization of native glycoprotein from pig small-intestinal mucus. Biochem. $J$. 195:267-275.

34. Kessler, M., O. Acuto, C. Storelli, H. Murer, M. Muller, and G. Semenza. 1978. A modified procedure for the rapid preparation of efficiently transporting vesicles from small intestinal brush border membranes. Biochim. Biophys. Acta. 506:136-154.

35. Lowry, O. H., N. J. Rosebrough, A. L. Farr, and R. J. Randall.
1951. Protein measurement with the Folin phenol reagent. J. Biol. Chem. 193:265-275.

36. Laux, D. C., E. F. McSweegan, and P. S. Cohen. 1984. Adhesion of enterotoxigenic Escherichia coli to immobilized intestinal mucosal preparations: a model for adhesion to mucosal cell components. J. Microbiol. Methods. 2:27-39.

37. Neumann, A. W., D. R. Absolom, W. Zingg, and C. J. Van Oss. 1979. Surface thermodynamics of leukocyte and platelet adhesion to polymer surfaces. Cell Biophys. 1:79-92.

38. Absolom, D. R., Z. Policova, T. Bruck, C. Thomson, W. Zingg, and A. W. Neumann. 1987. Surface characterization of protein coated polymer surfaces by means of the sedimentation volume method. $J$. Colloid Interface Sci. 117:550-564.

39. Absolom, D. R., F. V. Lamberti, Z. Policova, W. Zingg, C. J. Van Oss, and A. W. Neumann. 1983. Surface thermodynamics of bacterial adhesion. Appl. Environ. Microbiol. 46:90-97.

40. Absolom, D. R., W. Zingg, C. Thomson, Z. Policova, C. J. Van Oss, and A. W. Neumann. 1985. Erythrocyte adhesion to polymer surfaces. J. Colloid Interface Sci. 104:51-59.

41. Ofek, I., D. Mirelman, and N. Sharon. 1977. Adherence of Escherichia coli to human mucosal cells mediated by mannose receptors. Nature (Lond.). 265:623-625.

42. Ofek, I., and E. H. Beachey. 1978. Mannose binding and epithelial cell adherence of Escherichia coli. Infect. Immun. 22:247-254.

43. Dean, E. A., and R. E. Isaacson. 1985. Purification and characterization of a receptor for the $987 \mathrm{P}$ pilus of Escherichia coli. Infect. Immun. 47:98-105.

44. Gibbons, R. J., and I. Etherden. 1983. Comparitive hydrophobicities of oral bacteria and their adherence to salivary pellicles. Infect. Immun. 41:1190-1196.

45. Van Loosdrecht, M. C. M., J. Lyklema, W. Norde, G. Schraa, and A. J. B. Zehnder. 1987. The role of bacterial cell wall hydrophobicity in adhesion. Appl. Environ. Microbiol. 53:1893-1897.

46. Firon, N., I. Ofek, and N. Sharon. 1984. Carbohydrate-binding sites of the mannose-specific fimbrial lectins of Enterobacteria. Infect. Immun. 43:1088-1090.

47. Wadstrom, T., A. Faris, J. Freer, D. Habte, D. Hallberg, and A. Ljungh. 1980. Hydrophobic surface properties of enterotoxigenic $E$. coli (ETEC) with different colonization factors (CFA/I, CFA/II, K88 and K99) and attachment to intestinal epithelial cells. Scand. J. Infect. Dis. 12(Suppl. 24):148-153.

48. Wadstrom, T., A. Faris, M. Lindahl, S. Hjerten, and B. Agerup. 1981. A new principal for prevention of diarrhea caused by enterotoxigenic Escherichia coli (ETEC) possessing colonization factor antigen (CFA/I). Scand. J. Infect. Dis. 13:129-132.

49. Dillon, J. K., J. A. Fuerst, A. C. Hayward, and G. H. G. Davis. 1986. A comparison of five methods for assaying bacterial hydrophobicity. J. Microbiol. Methods. 6:13-19.

50. Mozes, N., and P. G. Rouxhet. 1986. Methods for measuring hydrophobicity of microorganisms. J. Microbiol. Methods. 6:99-112. 